\title{
A CONSTRUÇÃO DO REFERENTE EM UMA ANÁLISE DO PATHOS NA POLÊMICA
}

\author{
BUILDING THE REFERENT IN AN ANALYSIS OF PATHOS IN POLEMICS
}

\author{
Mariza Angélica Paiva Brito ${ }^{1}$, Rafael Lima de Oliveira ${ }^{2}$
}

\begin{abstract}
RESUMO: Este trabalho busca compreender como se constitui o apelo ao pathos dentro da polêmica discursiva, abordada por Amossy (2017), atualizada em comentários de postagens em páginas do Facebook. Para atingir esse objetivo, basear-nos-emos nos construtos teóricos de Aristóteles (2005), Plantin (2008), Charaudeau (2010) e Amossy (2017) acerca do pathos, e analisaremos a construção dos referentes com apoio em Custódio Filho (2011), Cavalcante e Brito (2016) e Cavalcante, Custódio Filho e Brito (2014), para fundamentar as evidências de certas disposições do locutor para representar os referentes conforme uma dada visão de mundo, a partir de valores partilhados socialmente. Tais valores também se relacionam, segundo Charaudeau (2010), à manifestação das emoções do sujeito.
\end{abstract}

PALAVRAS-CHAVE: pathos; argumentação; referenciação; estratégias.

ABSTRACT: This research seeks to understand how the appeal to pathos is constituted within the discursive polemic, explained by Amossy (2017), updated in comments on posts on Facebook pages. To meet this goal, we rely on theoretical constructs of Aristotle (2005), Plantin (2008), Charaudeau (2010) and Amossy (2017) about pathos, and to analyze the referents building process, we rely on Custódio Filho (2011), Cavalcante and Brito (2016) and Cavalcante, Custódio Filho and Brito (2014), to substantiate the evidence of certain provisions of the speaker to represent the referents according to a worldview and socially shared values. These values relate to the manifestation of the subject's emotions, according to Charaudeau (2010).

KEYWORDS: pathos; argumentation; referentiality; strategies.

\section{Introdução}

Desde a antiguidade clássica, discute-se o papel das emoções ${ }^{3}$ nas atividades humanas, com abordagens que perpassam a psicologia, a sociologia, a filosofia e os estudos da linguagem. No entanto, no que concerne aos estudos retóricos, mais precisamente dentro dos estudos da nova retórica de Perelman e Tyteca (2005), já no século XX, pode-se perceber uma

\footnotetext{
${ }^{1}$ Profa. do Instituto de Humanidades e Letras e do Mestrado Interdisciplinar em Humanidades / UNILAB. Pesquisadora da FUNCAP.

${ }^{2}$ Mestrando em Linguística da Universidade Federal do Ceará.

${ }^{3} \mathrm{O}$ termo grego pathos tem significados múltiplos e suas traduções são, por vezes, variadas, podendo ser encontradas como afetos, emoções, sentimentos, paixões, etc. As traduções e significações do termo foram tema de estudos filosóficos e terminológicos como o de Leite (2012). No entanto, evitamos essa variação terminológica agindo tal qual Charaudeau (2010), que opta pelo termo pathos, permanecendo, desta forma, à filiação retórica e, por outro lado, contribui para uma desassociação de estudos psicológicos e sociológicos.
} 
tendência à rejeição do elemento patêmico no argumento, que estabelecia uma "retórica sem emoções", como ressaltou Plantin (2008, p.122). Essa rejeição está intrinsecamente relacionada ao entendimento das emoções como um fator "desvirtuador", que enviesa e obscurece os raciocínios, equiparando-se a um mecanismo de manipulação, uma tentativa do orador de convencer a todo custo.

Contudo, dentro dos estudos contemporâneos de argumentação, linguistas como Christian Plantin e Ruth Amossy retomam o papel relevante do pathos dentro do jogo argumentativo, entendendo-o como fator indissociável, na medida em que acreditam que o sentimento tem suas razões, como postulou Amossy (2017). Isto significa dizer que as emoções não vão de encontro à racionalização e à reflexão, como nos fizeram crer alguns estudiosos e o senso comum, de uma maneira geral.

Este trabalho pretende, com auxílio teórico de Aristóteles (2005), Plantin (2008), Charaudeau (2010) e Amossy (2017), que de algum modo trataram das definições de pathos, compreender como se constitui o apelo ao pathos dentro da polêmica discursiva, discutida por Amossy em sua obra Apologia da Polêmica (2017). Para tanto, deter-nos-emos, especificamente, na análise da construção dos referentes dentro de comentários de notícias publicadas pela página do jornal Estadão e pela página da Arquidiocese de Porto Alegre no Facebook.

\section{Definições de pathos e suas relações com a argumentação}

É preciso fazer um retorno à retórica clássica para que entendamos as definições de pathos. Aristóteles não foi o primeiro a falar sobre o assunto, mas seus estudos acerca das emoções no jogo retórico são certamente basilares. O filósofo define, inicialmente, a retórica como "a capacidade de descobrir o que é adequado a cada caso com o fim de persuadir" (ARISTÓTELES, 2005, p.95-96). A partir deste ponto, três provas de persuasão são estabelecidas: o caráter moral do orador, o modo como se dispõem os ouvintes e o uso da linguagem, que, no grego, podemos fazer corresponder, respectivamente, à figura do ethos, do pathos e do logos.

Aristóteles (2005) diz que se persuade pela disposição dos ouvintes quando esses são levados a sentir emoção por meio do discurso, tendo em vista que os juízos que emitimos acerca das proposições variam de acordo com os sentimentos que nos são suscitados. A partir dessa compreensão acerca do pathos como prova de persuasão, podemos perceber o locutor 
como responsável por dispor os ouvintes, ou seja, estimulá-los, de maneira que esses estejam suscetíveis a sentir determinadas emoções que favoreçam a persuasão planejada pelo orador.

No segundo tomo de sua Retórica, o filósofo define as emoções como:

As causas que fazem alterar os seres humanos e introduzem mudanças nos seus juízos, na medida em que elas comportam dor e prazer: tais são a ira, a compaixão, o medo e outros semelhantes, assim como as suas contrárias (ARISTÓTELES, 2005, p. 160).

Aristóteles organiza 12 pathe, estabelecendo-os como emoções que se baseiam no prazer ou na dor, são elas: a cólera e a calma; a amizade e o ódio; o temor e a confiança; a vergonha e a gentileza; a piedade e a indignação; a inveja e a emulação. O orador teria, portanto, o objetivo de excitar ou neutralizar esses afetos de acordo com a situação argumentativa.

A partir da década de 1950, com a retomada dos estudos de argumentação após a deslegitimação da retórica no fim do século XIX, obras como a de Perelman e OlbrechtsTyteca (2005) propuseram uma "retórica sem emoções", como ressaltou Plantin (2008), que propôs uma reconstrução do papel das emoções nas questões argumentativas ao dizer que:

Se visarmos construir um modelo normativo da argumentação e se estimarmos que só se pode proceder à construção da razão argumentativa contra as emoções, normalmente faremos o controle passar a primeiro plano, isto é, eliminaremos as emoções. [...], mas se o objetivo é descrever a argumentação na intenção de compreender seus mecanismos, é preciso encontrar o modo de falar emoções. (PLANTIN, 2008, p. 123-124, grifo nosso)

Neste ponto, o teórico distingue três modos de tratar a emoção em argumentação: uma visão dos afetos como "paralogismos", entendo-os como falaciosos; uma teoria do paralelismo, que encapsula os afetos em "módulo emocional" paralelo ao "módulo lógico", atitude essa adotada pela retórica; e, por fim, uma teoria da "indiscernibilidade", perspectiva adotada por Plantin na qual nos pautamos nesse artigo, segundo a qual "é impossível construir um ponto de vista, um interesse, sem a eles associar um afeto, dado que as regras de construção e de justificação dos afetos não são diferentes da regra de construção e justificativa dos pontos de vista" (PLANTIN, 2008, p.124).

Essa perspectiva que não entende a construção passional como um "desvirtuante" da construção racional também é defendida por Amossy (2017), na medida em que acredita que a dissociação tradicional entre razão e paixão só pode induzir ao erro. Na retomada do conceito de pathos da retórica clássica, Amossy propõe um redimensionamento do pathos ao afirmar 
que este não só revela uma "tentativa de suscitar afetos no auditório", mas também expressa "um sentimento manifestado com veemência por um locutor profundamente implicado na sua proposta" (AMOSSY, 2017, p. 137), o que corrobora nossa compreensão de que seria inviável argumentar destituído de emoções.

Patrick Charaudeau (2010) nos diz que as emoções são origem de um comportamento, na medida em que se manifestam por meio das disposições de um sujeito, e são controladas (e até validadas) pelas normais sociais, já que o sujeito tem uma visão de mundo, julga esse mundo por meio de valores, os quais são objeto de um consenso social. Entretanto, o autor salienta que não é possível, por falta de meios metodológicos, estudar as emoções como realidade manifesta vivenciada por um sujeito, mas que se pode "tentar estudar o processo discursivo pelo qual a emoção pode ser estabelecida, ou seja, tratá-la como um efeito visado, sem nunca ter a garantia sobre o efeito produzido" (CHARAUDEAU, 2010, p. 34).

Partindo deste aspecto de uma análise do efeito visado, como propõe Charaudeau, questionamos qual contribuição a Linguística Textual (doravante LT) pode oferecer a uma análise da mobilização do pathos em textos geridos em polêmicas. Acreditamos que a análise da construção do referente dos textos, por exemplo, é um parâmetro oportuno para investigarmos.

\section{A polêmica discursiva e seus critérios definitórios}

Amossy (2017) entende a polêmica discursiva como um debate em torno de uma questão de atualidade, de interesse público. Partindo dessa definição, a teórica nos apresenta três critérios que definem a polêmica: a dicotomização de teses, a polarização social e a desqualificação do adversário. Falaremos sobre cada um desses critérios a seguir.

Para Amossy, a polêmica é um choque de opiniões antagônicas, e, assim sendo, “a oposição dos discursos, na polêmica, é o objeto de uma clara dicotomização na qual duas opções antitéticas se excluem mutualmente" (AMOSSY, 2017, p.53). Além disso, Amossy evoca a definição de King e Floyd (1971) para polarização ao apresentá-la também como um critério definitório. Para os autores, a polarização é um processo através do qual um público diversificado se funde em dois ou mais grupos, que se contrastam e mutualmente se excluem, que compartilham valores que o argumentador considera fundamental. Por fim, Amossy (2017) diz que a polarização não leva apenas a um movimento de reagrupamento por identificação, ela também marca um trabalho para a consolidação da identidade de um grupo, 
e isto necessariamente resulta em uma desqualificação do adversário, que passa a ser visto como um mal a ser combatido, um inimigo comum.

Na modalidade de argumentação polêmica, há uma estrutura actancial em que certos papéis são exercidos. Essa estrutura, segundo Macedo (2017), é composta por Proponente (aquele que defende uma das teses), Oponente (aquele que se opõe à tese do Proponente e defende a tese oposta) e o Terceiro (aquele que assiste ao debate e que ainda não se coloca na disputa). A polêmica se estabelece, portanto, na tentativa dos respectivos Proponentes de persuadir o Terceiro e de levá-lo a tomar as ideias de um dos grupos.

Compreendidos os critérios definitórios e a estrutura actancial da polêmica, perguntamos se é possível pensar em polêmica discursiva desprovida de emoções na medida em que nela encontramos locutores profundamente implicados em suas propostas. Para Amossy (2017), a simples presença da figura do pathos não é, de modo algum, suficiente para provar o caráter polêmico do discurso. Nosso trabalho defende a ideia de que, ainda que seja suficiente (nem poderia ser) para identificar a modalidade polêmica, a construção discursiva da emoção, como afirma Micheli, é "um traço característico do discurso polêmico, mesmo que esse traço não seja, propriamente falando, definitório e não possa, sozinho, servir para distinguir a polêmica de outros gêneros semelhantes" (MICHELI, 2010, p. 360). Assim, sustentamos a tese de que as modalidades argumentativas polêmicas têm como um de seus traços característicos o apelo às emoções.

\section{A violência verbal como uma manifestação do pathos}

Não se deve, no entanto, fazer equivaler emoção a violência verbal. Analisando as funções e limites da violência verbal, Amossy (2017) diz que esta não se configura também como um traço definitório, mas como um auxiliar, sendo, assim como o pathos, um intensificador da dicotomização, da polarização e, principalmente, do descrédito ao adversário. Não entendemos, com essa afirmação, que a violência verbal esteja desvinculada da figura do pathos, mas que, havendo violência verbal, há necessariamente pathos, mas que a figura do pathos não implica, necessariamente, em violência - e aí estendemos a violência não apenas à verbal.

A seguir, apresentaremos três dentre os sete parâmetros elencados por Amossy (2017) para a configuração da violência verbal. Concordamos com Maingueneau (2008) quando afirma que é difícil traduzi-la em termos linguísticos. 
O primeiro parâmetro que selecionamos diz respeito à situação em que o ponto de vista apresentado pelo Oponente é totalmente desconsiderado, ou ridicularizado, tornando-o objeto de um reductio ad absurdum (redução ao absurdo). Outro parâmetro é quando se ataca a própria pessoa do Oponente, no caso do argumento denominado ad hominem. Por fim, destacamos o caso em que o pathos se expressa por violência verbal:

O polemista exprime sentimentos violentos que se inscrevem por marcas lexicais, sintáticas e prosódicas. A agressividade se origina aqui do fato de que o locutor parece agitado por sentimentos fortes suscitados pelo Oponente e dirigidos contra ele. Essa emoção se traduz no plano lexical ou nas exclamações, nas repetições fáticas, no ritmo (AMOSSY, 2017, p. 171)

É neste ponto que adotamos a hipótese de que parâmetros de análise da LT (ver Cavalcante, 2016) possam contribuir para uma análise do pathos (e aqui, mais especificamente, da violência verbal), pois, além do plano lexical e da organização sintática, outros critérios podem evidenciar essas marcas, como a construção do referente dentro de um texto.

\section{O ambiente da rede social na polêmica discursiva}

Faz-se mister que contextualizemos o ambiente da rede social Facebook para que compreendamos de que forma o funcionamento de suas postagens e de seus comentários sancionam certas ações que em outros ambientes não seriam toleradas. As redes sociais como um todo nos parecem ambientes propícios para o uso de violência verbal. Amossy nos diz que "as interações pelo computador são apontadas por alguns como lugar de livre curso de uma violência desenfreada e perigosa, enquanto outros reconhecem nela um instrumento de participação cidadã e de democratização" (AMOSSY, 2017, p. 173).

Além disso, há de se ressaltar que poucos são os casos em que os usuários da rede se preocupam com as devidas preservações de face, diferentemente do que acredita Amossy (2017, p. 173) ao dizer que o uso de pseudônimo é uma regra no que diz respeito à violência verbal na internet. No entanto, o Facebook não nos parece um ambiente em que a violência verbal ocorra por intermédio de "avatares". Isso pode estar acontecendo por duas possíveis causas: existe um desconhecimento por parte dos usuários acerca de crimes cibernéticos, como a difamação, ou estes podem crer que tais crimes não são punidos. Desta forma, eles utilizam a rede (criando postagens e/ou comentando postagens) com o uso frequente da violência verbal. 
A violência verbal é, portanto, sancionada, isto é, "permitida" pelo ambiente em que ocorre. Ressaltamos a utilização de aspas em permitida porque, oficialmente, se tomarmos como base as diretrizes de uso da rede, certas atitudes podem ser denunciadas pelos usuários e, consequentemente, chegar a ser apagadas pela própria rede. No entanto, os ataques continuam a acontecer com frequência.

Compreendendo essa sanção como um fator importante para o acirramento de polêmicas e como um potencializador para a desqualificação do adversário, partimos agora para compreender um recurso da rede que nos é imprescindível para o início de nossa análise - as reações.

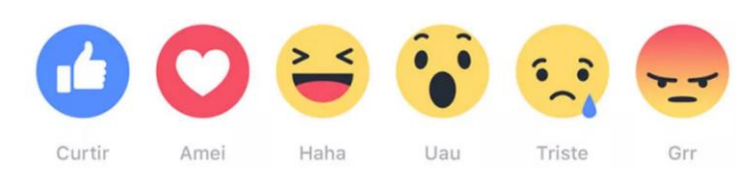

Figura 1 - As reações do Facebook (Imagem do Facebook).

Anteriormente, o Facebook dispunha apenas do botão "curtir" para os usuários interagirem com as postagens lá publicadas. Na medida em que seus criadores perceberam que o botão "curtir" não atendia a certas necessidades de seus usuários, o recurso das reações foi criado, possibilitando que, além de curtir, eles pudessem dar "amei" (que demonstra, por parte do usuário, forte aprovação a uma atualização publicada na rede), "haha" (voltado para conteúdos engraçados), "uau” (para quando algo lhe surpreende), "triste” (para situações nas quais o "curtir" pode soar ofensivo, como numa postagem que anuncie o falecimento de alguém) e "grr" (que pode ser usado para demonstrar raiva ou total desaprovação com o conteúdo publicado).

Os criadores do Facebook acreditam que as reações demonstram um nível mais alto de engajamento por parte do usuário. "Curtir" uma postagem é mais fácil e automático, então, se o usuário gastou alguns segundos a mais para reagir a uma publicação, isso significa que, para o bem ou para o mal, ele está mais envolvido com aquele conteúdo. É neste ponto que retomamos o conceito reformulado por Amossy (2017) acerca do pathos, quando este revela "um sentimento manifestado com veemência por um locutor profundamente implicado com sua proposta". Desta forma, sugerimos que "reagir" a uma postagem seja uma possível evidência de um locutor (ou usuário) implicado com sua proposta, na medida em que reagir demonstra maior engajamento do usuário. 


\section{Uma análise da construção do referente na polêmica}

Se defendemos aqui uma teoria da "indiscernibilidade" (PLANTIN, 2008), a qual nos diz que é impossível construir um ponto de vista sem a ele associar um afeto, e entendermos as emoções, tal qual Charaudeau (2010), como originadas de um comportamento, na medida em que se manifestam por meio das disposições de um sujeito, podemos acreditar que é possível, através de uma análise das etapas de manutenção e progressão dos referentes em redes referenciais do texto como estratégias argumentativas, evidenciar a mobilização do pathos. Para tanto, recorreremos a Cavalcante (2011), a Cavalcante, Custódio-Filho e Brito (2014) e a Cavalcante e Brito (2016).

Os exemplos que apresentaremos neste artigo são comentários às postagens da página do Jornal Estadão e da Arquidiocese de Porto Alegre no Facebook e estão dentro de um mesmo contexto: a polêmica envolvendo a Exposição Queer Museu promovido pelo Santander Cultural. As imagens da exposição chegaram à internet em setembro de 2017, ocasionando críticas por parte dos usuários. A exposição foi acusada de trazer obras com blasfêmia a imagens religiosas e com apologia à pedofilia, o que levantou debates acerca do que se considera arte.

Milhares de pessoas comentavam e debatiam sobre o assunto a cada notícia publicada acerca do caso pelos jornais em redes sociais. Selecionamos apenas alguns comentários e seus respectivos desdobramentos (respostas ao comentário) por acreditar que estes, por si sós, são suficientes para o que pretendemos. Os comentários na postagem do Jornal Estadão são referentes à notícia "MPF recomenda que Santander reabra a exposição Queermuseu", que ressaltava uma posição dada pelo Ministério Público Federal. Este posicionamento favorável do MPF à exposição gerou fortes ataques por parte de alguns usuários que a condenavam. 
Departamento jurídico do Santander Cultural já foi comunicado (via Cultura Estadão) \#Estadao

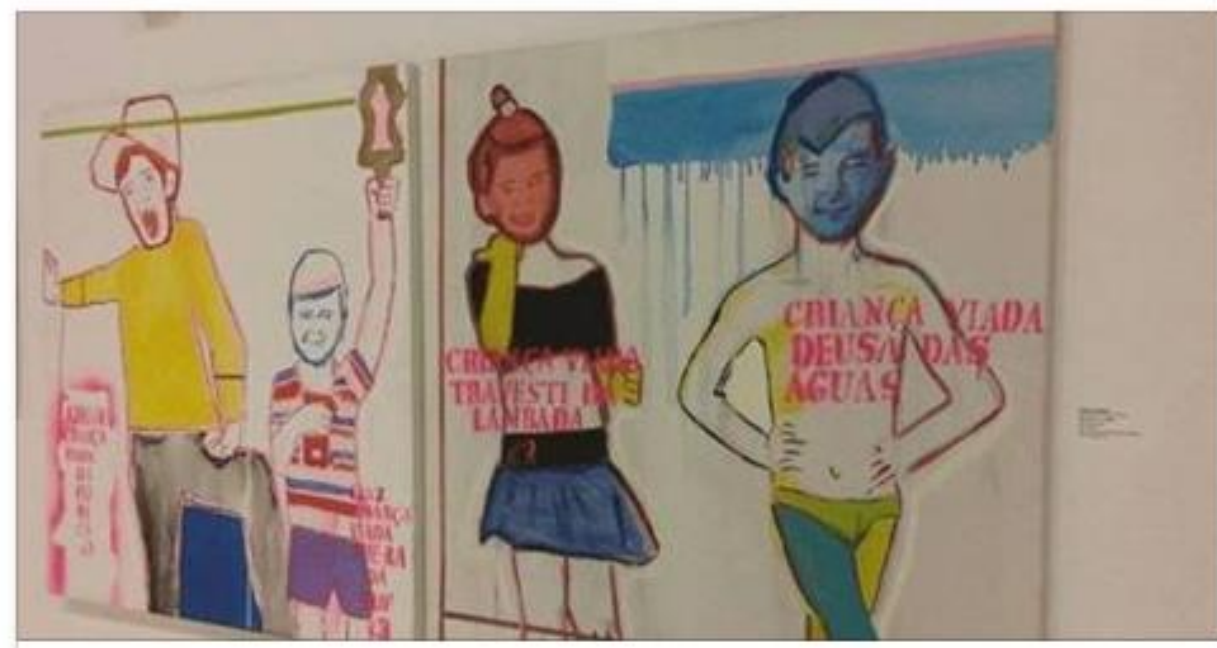

MPF recomenda que Santander reabra a exposição Queermuseu

CULTURA.ESTADAO.COM.BR

(3) Curtir

\section{Comentar}

(1) 4,5 mil

323 compartilhamentos

Figura 2 - Print de uma postagem de notícia do Estadão (Disponível em: <https://www.facebook.com/estadao/posts/2156976700984047>. Acesso em 25 mar. 2018)

\section{(1) $1,8 \mathrm{mil} \& 1,6 \mathrm{mil} \odot 898$ \& 99 :0 $31 \quad \because 30$}

Figura 3 - Ampliação das reações à notícia anterior (Imagem do Facebook).

Já os comentários na postagem da página da Arquidiocese de Porto Alegre dizem respeito à nota da própria Arquidiocese sobre a exposição no Santander Cultural. 


\section{Arquidiocese De Porto Alegre}

11 de setembro de 2017 .

Nota da Arquidiocese de Porto Alegre sobre exposição no Santander Cultural

A comunidade de fé na Arquidiocese de Porto Alegre manifesta sua estranheza diante da promoção da exposição realizada junto ao Santander Cultural, na capital gaúcha, que utiliza de forma desrespeitosa símbolos, elementos e imagens, caricaturando a fé católica e a concepção de moral que enleva o corpo humano e a sexualidade como dom de Deus.

É urgente combater o preconceito e a discriminação em todas as suas manifestações. Nesse sentido, em nome da pluralidade e do respeito às minorias, temos assistido ataques discriminatórios à cultura judaico-cristã que contribuiu na formação cultural do ocidente. Eliminar as dificuldades jamais pode significar desrespeitar o outro e suas crenças, especialmente porque, ao se tratar do imaginário simbólico da fé, entra-se num campo delicado de significados e sentidos que a ninguém é dado o direito de desprezar. Em tempos de terrorismo e intolerância, não se constroem pontes com agressão e desrespeito pelo o que é mais íntimo e sagrado no outro: sua fé e seu corpo.

Continuemos trabalhando por um humanismo solidário com uma atitude de paz que não precisa agredir e ofender quem tem pensamento diferente. São Francisco de Assis, medieval e cristão que continua a iluminar a contemporaneidade, ensina-nos a ver o outro como irmão e nos faça a todos instrumentos de paz!

Porto Alegre, 11 de setembro de 2017

Assessoria de Comunicação da Arquidiocese de Porto Alegre

Figura 4 - Print da nota publicada pela Arquidiocese de Porto Alegre sobre a exposição no Santander Cultural (Disponível em: < https://goo.gl/U28vDu >. Acesso em 25 mar. 2018)

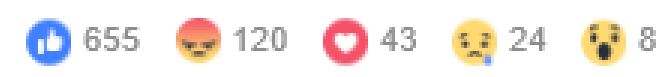

Figura 5 - Ampliação das reações à nota da Arquidiocese (Imagem do Facebook).

Em ambos os casos, a reação mais realizada logo após o automático botão "curtir" é a reação "grr”, que indica uma postura raivosa dos usuários frente às postagens. Não se trata de uma mera coincidência, os engajamentos dos leitores em dar essa reação já anunciam a maneira como serão desenvolvidos os comentários nas respectivas postagens: com ataques agressivos, seja ao Santander e aos defensores da exposição, seja ao MPF ou a Arquidiocese.

A partir deste ponto, analisaremos alguns comentários de ambas as postagens no intuito de identificar como os referentes nos comentários são introduzidos e recategorizados em suas retomadas anafóricas dentro do texto, levando a forte manifestação de violência verbal e de desqualificação do adversário. Comecemos, pois, com os comentários na postagem do Estadão. 


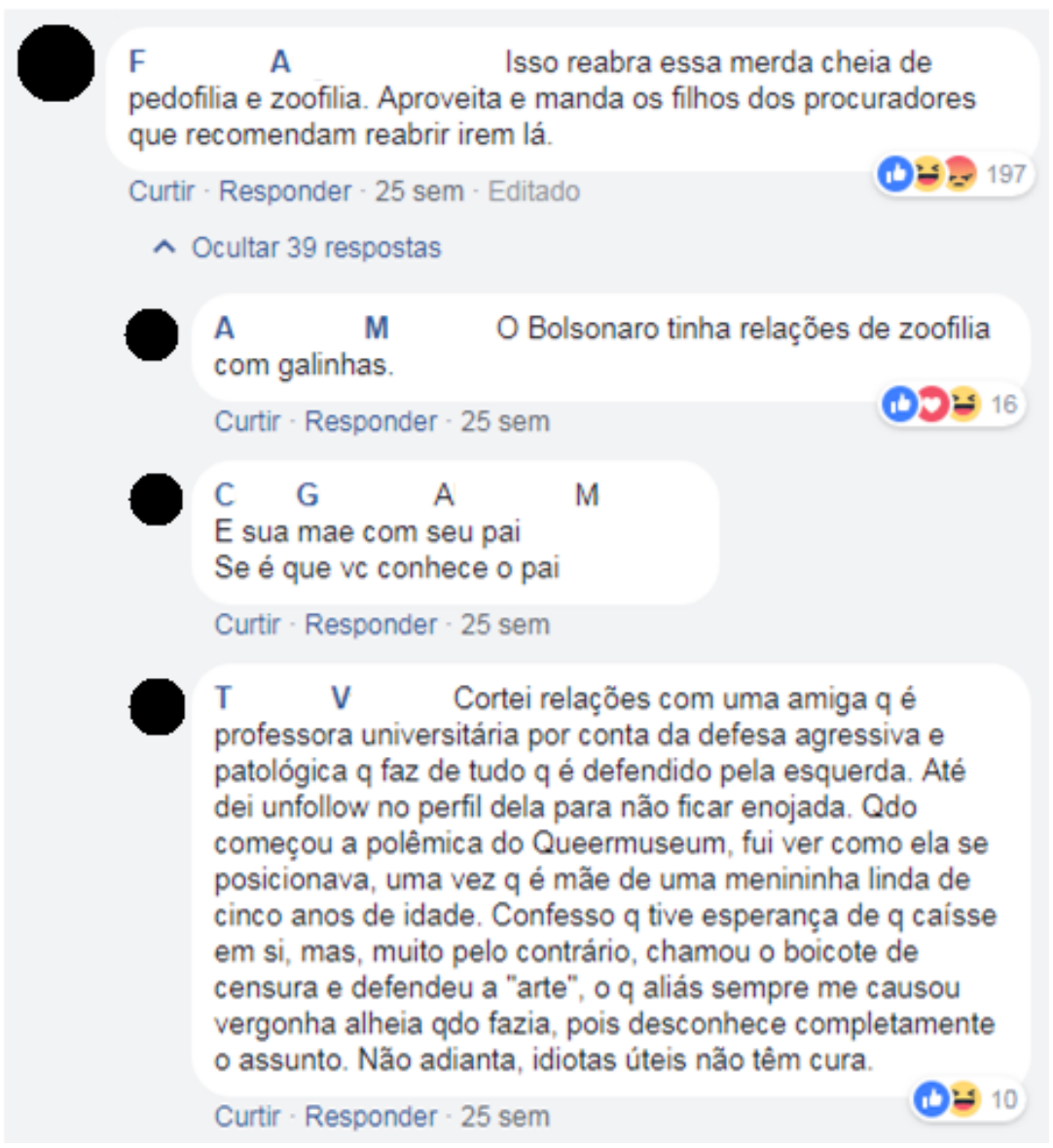

Figura 6 - Print dos comentários da postagem do Estadão.

O locutor F.A inicia com uma imediata introdução (que recategoriza a exposição Queermuseu) como uma "merda", cheia de pedofilia e zoofilia. A utilização desse termo ofensivo e repleto de acusações já revela de imediato o posicionamento do locutor do comentário. Não fosse bastante, F.A prossegue com "Aproveita e manda os filhos dos procuradores que recomendam reabrir irem lá”, que, a nosso ver, já se configura como um ataque ad hominem (quando se ataca a moralidade e a personalidade do Proponente e não seus argumentos), na medida em que se construímos o raciocínio: a exposição é cheia de pedofilia e zoofilia, logo a exposição é uma "merda", portanto, a ida dos filhos dos procuradores à exposição se configura, na visão de F.A, como um ataque.

A partir dessa postagem, foram publicadas 41 respostas a ela. Selecionamos algumas dessas para analisar. A primeira diz "O Bolsonaro tinha relações de zoofilia com galinhas". Em um primeiro momento, chega a parecer incoerente o comentário de A.M frente ao que foi dito por F.A com a introdução do referente Bolsonaro, no entanto, é preciso esclarecer o que leva a esse raciocínio que também é entendido como um ataque ad hominem, nesse caso, à figura do deputado. A linha de raciocínio desenvolvida por A.M é uma espécie de silogismo no qual diz: se você é contra a exposição, logo você é uma pessoa conservadora. Se você é 
uma pessoa conservadora, logo você é uma pessoa que apoia as ideias de Jair Bolsonaro. Portanto, atacar Bolsonaro significa atacar as ideias conservadoras que você defende e, consequentemente, atacar você. É neste momento que fica claro por que A.M optou por introduzir um referente que aparentemente não teria relação com o que foi dito, pois desta forma não só faria ataque à figura de Bolsonaro, como também às ideias conservadoras que o deputado e seus seguidores defendem.

O comentário de C.G que vem em seguida não responde necessariamente ao comentário de F.A, na verdade, C.G responde A.M. Quando diz "E sua mãe com seu pai, se é que vc conhece pai", o locutor estabelece claramente um ataque a figura da mãe de A.M, pois, se compararmos com o comentário feito por A.M, veremos que o intuito de C.G teria sido o de chamar a mãe de A.M de "galinha" e que, consequentemente, seu pai teria agido tal qual Bolsonaro. Só entendemos essa relação que se estabelece entre a galinha e a mãe de A.M se entendermos todos os comentários como textos que se relacionam.

O comentário de T.V relata um desentendimento do locutor com uma amiga na medida em que esta defende de maneira "agressiva e patológica" tudo o "que é defendido pela esquerda". O termo "esquerda" aqui diz respeito ao posicionamento mais libertário dos partidos de esquerda acerca de tabus como esse. Mais à frente, T.V diz que buscou saber o posicionamento da amiga acerca do assunto, uma vez que ela era mãe de uma criança de cinco anos. O raciocínio desenvolvido até aqui também é uma espécie de silogismo: se você tem filhos menores de idade, logo você é contra a exposição, na medida em que esta apresenta obras com apologia à pedofilia. No entanto, o desentendimento com a amiga é justamente pela quebra desse raciocínio esperado e relatado indiretamente pela locutora.

Em seguida, ela traz a voz da amiga, que recategoriza o boicote à exposição de "censura". A locutora diz que a amiga defendeu a exposição chamando-a de "arte" (com a utilização das aspas indicando não só uma ironia frente à recategorização estabelecida pela amiga, mas também o afastamento e a discordância da autora frente ao posicionamento). Por fim, T.V parte para o ataque ad hominem quando diz "Não adianta, os idiotas não têm (sic) cura", dado que "os idiotas", neste caso, seriam uma maneira de recategorizar seus Oponentes, incluindo a amiga, que defendem a exposição. 


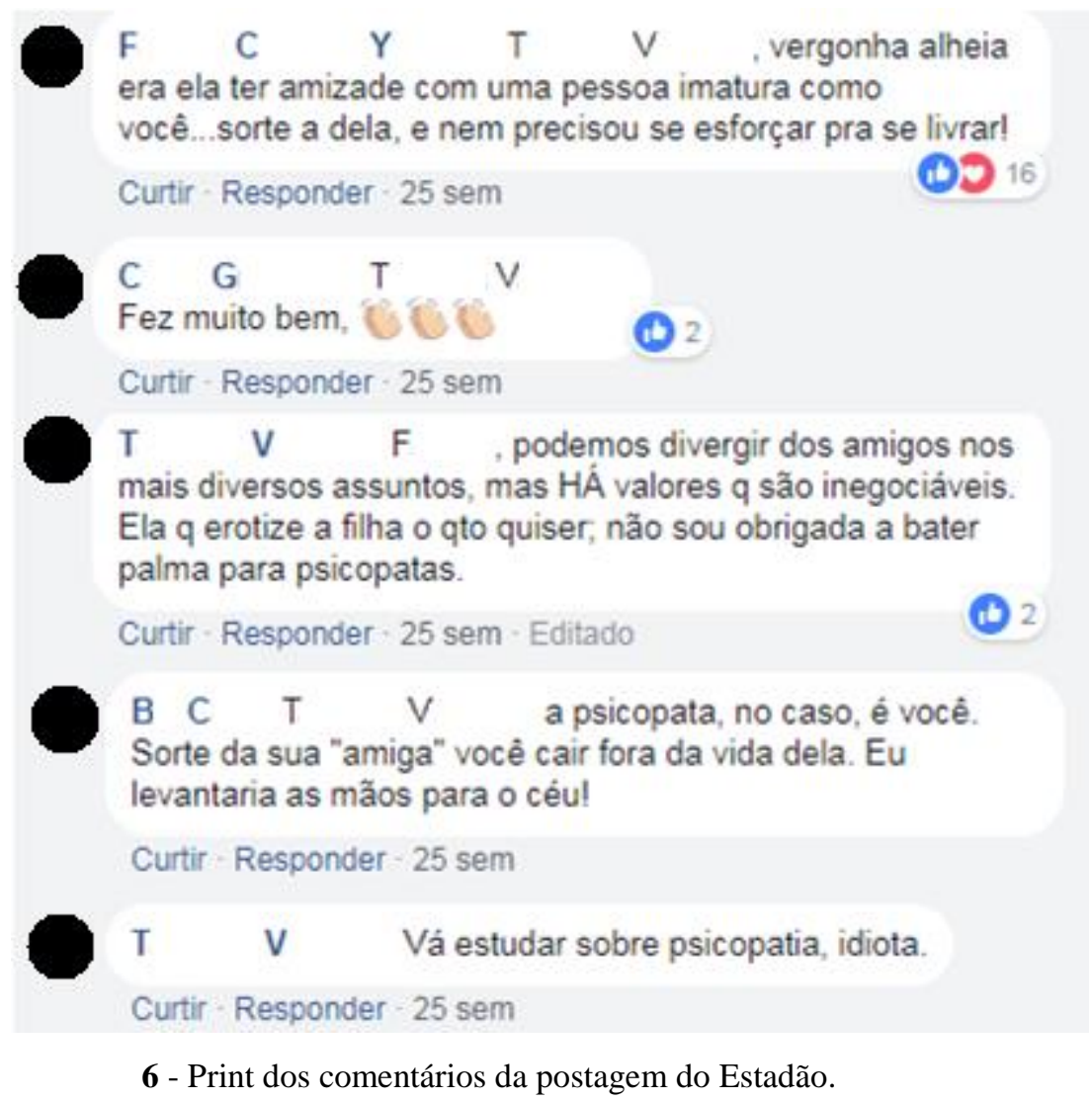

Assim como costuma ocorrer nesse ambiente, muito dos comentários que se seguem não se relacionam propriamente ao comentário inicial. São respostas a outras respostas, como essas que vemos acima, as quais reagem ao último comentário que analisamos. F.C.Y retoma o termo "vergonha alheia" utilizado por T.V, quando disse ter vergonha alheia do posicionamento da amiga acerca do que é arte, recategorizando-o ao dizer que, na verdade, "vergonha alheia é ter uma amizade com uma pessoa imatura como você". O oponente, desta forma, também se utiliza do ad hominem. Podemos perceber que o comentário de F.C.Y recebeu 16 reações, dentre elas, as reações “amei”, que demonstram uma forte aprovação.

C.G apoia o posicionamento de T.V. Em seguida, T.V responde à ponderação que retoma o termo "vergonha alheia", mas não o ataca e, sim, permanece atacando a amiga, na medida em que diz "ela q erotize a filha o qto quiser", acusando a amiga de erotizar a filha, visto que ela é favorável à exposição. Por fim, depois de intitular os Oponentes como "idiota", T.V recategoriza o referente intitulando "psicopatas", passando de um insulto comum a uma terminologia patológica mais agressiva.

O comentário de B.C reverte a acusação de ser "psicopata", na medida em que ele também se posiciona a favor da exposição, dizendo que, na verdade, o "psicopata" é T.V. Por fim, B.C salienta, com auxílio do uso de aspas, que a amiga de T.V nunca foi, de fato, sua amiga, tendo em vista o modo agressivo e insultante de como T.V se referiu a ela. O locutor 
T.V, por fim, responde à B.C exigindo que esse estude sobre a psicopatia e o chama de "idiota" novamente.

Partiremos, agora, para os comentários à nota da Arquidiocese acerca da exposição. Selecionamos, para isso, cinco dos comentários com mais reações. Vejamos:

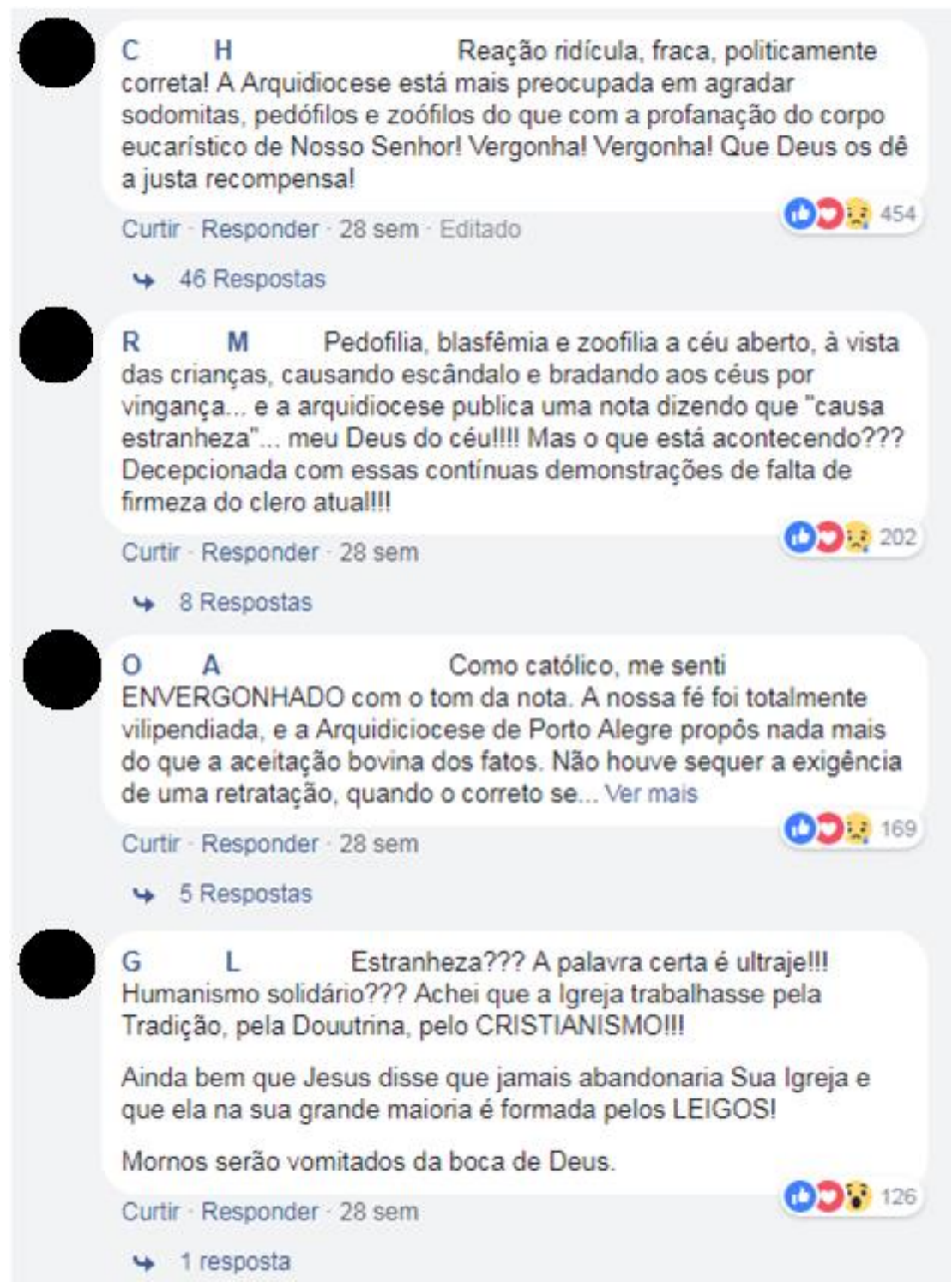

7 - Print dos comentários da postagem da Arquidiocese de Porto Alegre.

C.H já se inicia intitulando, ou melhor, recategorizando o referente "nota da Arquidiocese de Porto Alegre" como reação "fraca", "ridícula" e "politicamente correta", isso porque a nota apontou sua "estranheza diante da promoção da exposição" e as pessoas se incomodaram com a postura pacífica adotada pela Arquidiocese. Ao dizer que "A Arquidiocese está mais preocupada em agradar sodomitas, pedófilos e zoófilos", o que o locutor do comentário faz é atacar a moral de seus Oponentes, chamando-os dessa forma. Por fim, C.H retoma o referente da "nota" e o chama de "vergonha", ressaltando seu posicionamento contrário à pacificidade da Arquidiocese e, também, à exposição. 
O comentário de R.M, neste caso, inicia recategorizando o referente "exposição Queermuseu” como "pedofilia, blasfêmia e zoofilia a céu aberto, a vista das crianças". Frente à forma como recategoriza a nota, o locutor se indigna e utiliza as aspas em "causa estranheza", não só por retomar como citação a postura da Arquidiocese, como também para implicar uma ironia a essa postura. Por fim, o locutor entende a postura pacífica da Arquidiocese como "demonstrações de falta de firmeza do clero atual".

O comentário de O.A também deixa implícito que a nota é uma "vergonha" para os católicos e se revolta contra a postura apaziguadora da Arquidiocese. O comentário de G.L inicia questionando e retomando o termo "estranheza" seguido de diversos pontos de interrogações, marcas que, segundo Amossy (2017), traduzem estados de emoção. Em seguida, o locutor recategoriza à exposição como "ultraje", ou seja, como um insulto, uma ofensa grave. Ao utilizar os termos G.L não só demonstra seu posicionamento em relação à exposição como demonstra também sua expectativa quanto à postura da Arquidiocese em relação à exposição. Por fim, G.L chama os atuantes da igreja que se posicionaram de modo pacífico de "leigos" e diz que "os mornos", uma anáfora para os que escreveram a nota da Arquidiocese, "serão vomitados da boca de Deus", ou seja, serão excluídos.

\section{Considerações finais}

A partir dos comentários analisados, podemos confirmar que os debates inflamados e agressivos ganham força em ambientes como o Facebook por ser, a nosso ver, ambientes propícios para o uso de violência verbal. Além disso, fica clara a completa despreocupação dos usuários em relação à preservação de suas devidas faces, diferentemente, como vimos, do que acredita Amossy (2017). Os usuários agem normalmente comentando com seus próprios perfis, que evidenciam as suas imagens e os seus nomes (que aqui omitimos por questões éticas).

No que concerne aos parâmetros da violência verbal elencados por Amossy (2017), foi possível notar que há um uso frequente do argumento denominado ad hominem, em que o Proponente não ataca a tese de seu adversário, mas a própria pessoa do Oponente. Vimos também, nos comentários dirigidos à Arquidiocese, usuários que se utilizam do reductio ad absurdum, na medida em que enquadram o posicionamento pacífico da Arquidiocese como "ridículo", "fraco", "digno de sentir vergonha" e "piada", pois o que os usuários pretendem, desta forma, é desconsiderar e ridicularizar o ponto de vista apresentado pela instituição.

Como resultado de nossa análise, foi possível confirmar também que a forma como os usuários dispõem os referentes no texto, introduzindo-os e retomando-os de forma 
recategorizadora (como vimos em relação à exposição, ao Oponente, à Arquidiocese, ao MPF, etc.), revela os sentimentos manifestados de locutores profundamente implicados em suas propostas, pois a maneira como introduzem e retomam os referentes está completamente relacionada a uma dada visão de mundo e a partir de valores partilhados socialmente. Esses valores, nesta situação, são mais conservadores (como alguns comentários chegaram a ressaltar).

Além dessas questões relacionadas ao discurso de ódio e à violência verbal, foi possível notar que muitos comentários que trouxeram a figura da criança em relação à exposição ("pedofilia, blasfêmia e zoofilia a céu aberto, a vista das crianças", a exemplo) buscavam apelar ao pathos na medida em que se criava um ambiente de indignação e repugnância para o Terceiro, ao relacionar menores de idade a conteúdos eróticos, pois a maioria das pessoas teria aversão e iriam aderir à tese do Proponente.

\section{REFERÊNCIAS}

ALMEIDA, P. S. Elementos textuais para uma análise argumentativa do discurso. 97f. Projeto de tese (Doutorado em Linguística). Universidade Federal do Ceará, Fortaleza, 2017.

AMOSSY, R. Apologia da polêmica. São Paulo: Contexto, 2017.

ARISTÓTELES. Retórica. 2a . ed., revista. Lisboa: Imprensa Nacional-Casa da Moeda, 2005.

CAVALCANTE, M.M.. Abordagens da argumentação nos estudos de Linguística Textual. Revista Virtual de Estudos da Linguagem, v. 14, p. 106-124, 2016.

; BRITO, M. A. P. O caráter naturalmente recategorizador das anáforas. In: AQUINO, Z. G. O.; GONÇALVES-SEGUNDO, P. R. (Orgs.). Estudos do discurso: caminhos e tendências [Internet]. São Paulo: Paulistana, 2016. Disponível em: http://cied.fflch.usp.br/sites/cied.fflch.usp.br/files/u31/Livro-CIED-2016-final.pdf. Acesso em: $<25$ nov. 2016>.

.; CUSTÓDIO FILHO, V.; BRITO, M. A. P. Coerência, referenciação e ensino. São

Paulo: Cortez, 2014.

CHARAUDEAU, P. A patemização na televisão como estratégia de autenticidade. In: MENDES, E.; MACHADO, I. L. (Orgs.). As emoções no discurso, volume II. Campinas: Mercado de Letras, 2010.

CUSTÓDIO FILHO, V. Múltiplos fatores, distintas interações: esmiuçando o caráter heterogêneo da referenciação. 330 f. 2011. Tese (Doutorado em Linguística) - Programa de Pós-graduação em Linguística, Universidade Federal do Ceará, Fortaleza, 2011.

KING, A.; FLOYD, D. A. Nixon, Agnew, and the 'Silent Majority': a Case Study in the Rhetoric of Polarization. Western Speech, 1971, p. 243-255.

MAINGUENEAU, D. Sémantique de la polemique. Lausanne: L'Âge d'Homme, 1983.

MICHELI, R. L'émotion argumentée. L'a abolition de la peine de mort dans le débat parlementaire français. Paris: Le Cerf, 2010.

PERELMAN, C.; OLBRECHTS-TYTECA, L. Tratado de argumentação: a nova retórica. Tradução Maria Ermantina de Almeida Prado Galvão. 2 ed. São Paulo: Martins Fontes, 2005. PLANTIN, C. A Argumentação. São Paulo: Parábola Editorial, 2008. 